folk/ed. Derg, 2021; 27(4)-108. sayı

DOI: $10.22559 /$ folklor.1794

\title{
Çeviribilim ve Çeviri Olgusu Açısından İdeoloji
}

\author{
Translation Studies and Ideology in terms of Translation
}

\author{
Nurdan Maral ${ }^{*}$ \\ Faruk Yücel $^{* *}$
}

Öz

Çeviri eylemi ve olgusunun dilbilimsel/metinsel ya da iletişimsel aktarıma indirgenemeyeceği gerçeği, artık çeviri alanında araştırma yapan ve çevirinin toplumdaki işlevi hakkında düşünen herkesin kabul ettiği bir gerçektir. Tek düzlemli bir aktarım olarak ele alınmaması gereken çeviri olgusu, zaman/uzama bağlı görece bir güç aracına dönüşebilir. Tarih boyunca düşüncenin gelişmesinde ve değişmesinde önemli rol oynayan dini, siyasi, felsefi ve bilimsel metinlerin oluşumunda ya da üretilmesinde çevirilerin etkisi düşünüldüğünden daha fazladır. Toplumlar, sosyal tarihi biçimlendiren düşünce ve kültürlerin gelişmesinde kaçınılmaz olarak birbirlerini olumlu ya da olumsuz etkilemiştir. Bu etki alanlarından biri kuşkusuz çeviri ile ilgilidir. Bunun nedeni, metinlerin toplumu şekillendirmede en etkili araçlardan biri olmasıdır. Çeviriler bir toplumda ya da kültürde algı yönetimini

Geliş tarihi (Received): 31-03-2021 - Kabul tarihi (Accepted): 25-07-2021

* Doktora Öğrencisi, Ege Üniversitesi Sosyal Bilimler Enstitüsü Çeviribilim Programı (Ph.D. Student, Ege University Social Sciences Institute Translation Studies Program) nurdanmaral@gmail.com.ORCID 0000-0002-3354-8908

** Prof. Dr., Ege Üniversitesi Edebiyat Fakültesi Mütercim ve Tercümanlık Bölümü. (Ege University, Faculty of Letters, Department of Translation and Interpretation) faruk.yucel@ege.edu.tr. ORCID 0000-0003-2027-882X 
biçimlendirmede bir araç olarak da kullanılabilmektedir. Çeviri denilen ürünler, belli bir zaman ve uzamda bir güç odağı tarafından planlı ve kasıtlı belli bir etki yaratarak toplumu değiştirmeye ya da yönlendirmeye çalışılıyorsa, burada ideolojik bir yapılanmadan söz edilebilir. Bu çalışmada, çeviribilim çalışmalarında ideoloji kavramının nasıl tartışıldığı ve çeviri sürecinde alınan kararlarda ideolojinin etkisi ele alınmaktadır. Bu bağlamda, ideoloji kavramının açılımı ve anlamı sorgulanarak ideolojinin çeviri ile olan ilişkisi irdelenmektedir.

Anahtar sözcükler: çeviribilim, ideoloji, çevirmen kararlarl, çeviri süreci

\begin{abstract}
The act and phenomenon of translation cannot be reduced to mere linguistic / textual or communicative transfer, an argument agreed by all researchers in the field and others interested in the function of translation in society. The phenomenon of translation should be seen not as transfer on a single level, but as a tool, whose power is related to developments in a particular time and space. Thus, the effects of translations may have been underestimated, since translation is important in the formation or production of religious, political, philosophical and scientific texts that have played an important role in the development and change in thought throughout history. Societies have inevitably influenced each other, both positively or negatively, in shaping the ideas and cultures throughout history. Translation is undoubtedly one of the means by which this influence occurs. Translations can also be used as a tool for perception management in a society or culture. The products called as translation may attempt to change or direct society through certain planned and deliberate effects via a power focus at a certain time and space, thus creating an ideological structuring. This study provides a discussion of the concept of ideology in translation studies, and the effect of ideology on the decisions taken in the translation process. In this context, this study examines the meaning of the concept of ideology, and also its relationship with the concept of translation.
\end{abstract}

Keywords: translation studies, ideology, translator's decisions, translation process

\title{
Extended summary
}

Introduction: The act and phenomenon of translation cannot be reduced to mere linguistic / textual or communicative transfer, an argument agreed by all researchers in the field and others interested in the function of translation in society. The phenomenon of translation should be seen not as transfer on a single level, but as a tool, whose power is related to developments in a particular time and space.. Thus, the effects of translations may have been underestimated, since these are important in the formation or production of religious, political, philosophical and scientific texts, which have played an important role in the 
development and change in thought throughout history. Societies have inevitably influenced each other, whether positively or negatively, in shaping the ideas and cultures throughout history. Translation is undoubtedly one of the means by which this influence occurs; and in this respect translations can be used as a tool for perception management in a society or culture. The products called translation may attempt to change or direct society through certain planned and deliberate effects at a certain time and space, via a power focus, thus creating an ideological structuring. In this regard, texts/translations are extremely effective tools in shaping societies. Although texts are created by individuals and institutions in a particular society, new texts can be adopted in a society from different languages and cultures through translation. However, this will not necessarily be for the benefit of that society. Here, it should be considered by whom the translations are made, and for what purpose. An act done with a certain purpose and intention can become an ideological tool, including an act of translation. As Thompson emphasizes, the concept of ideology is considered in the context of descriptive concepts used by social sciences and as "thought systems", "belief systems" or "symbolic systems" peculiar to social action or political practice, as a neutral ideological way of thinking (2013: 14). This study provides a discussion of the concept of ideology in translation studies, and its effect on the decisions made in the translation process. In this context, this study examines the meaning of the concept of ideology, and also its relationship with the concept of translation.

Literature Review: According to Humboldt, language is a formative activity that participates in the process of producing ideas and forming concepts beyond being a structure consisting of simply putting words together (Humboldt, 1988: 51). Humboldt adds that the language of a nation cannot be independent of that nation's worldview. This worldview determines and develops language (Akarsu, 1998: 42). Therefore, thoughts create language, but the reverse is also true (1998: 43). Based on the argument that language determines thought and thought determines language, transferring a thought to another culture and language for certain purposes can also be interpreted as bringing a deliberate?? change in the language accordingly. The translation process, which is the transfer of a work between languages, and also a decision-making process, not only involves the explicit ideology of the decision maker, but also indicates a sufficiently ideological behavior, even when it is apparently guided by no ideological goals or views (Kanca, 2009: 77). In this context, it can be said that in every translation, ideological choices are made, whether consciously or unconsciously. Basil Hatim and Ian Mason define a translator as being at the very center of translation, which is a very dynamic process, and is an intermediary between the producer of the source text and the target recipients of the text (1990: 223). Furthermore, they state that translators are the first readers of the source texts and, unlike an ordinary reader, are responsible for conveying the source text as impartially as possible, unbiased by individual ideology, beliefs or values in the translation. (Hatim ve Mason, 1990: 223, 224). However, this is not in fact possible; Tymoczko argues that the ideological effect can vary between 
translations, even of the same text, because ideology is not only implicit in the translated text, but also in the recipient audience, and in the translator's voice and stance. She also argues that the variables of ideological position held by translators' are directly related to their role in the process. (2014: 181).

Conclusion: It is impossible to consider the shaping of the translation, literary and cultural system independent of ideology, and accordingly, the use of language develops towards a specific function and is shaped according to social norms/expectations. This ideological attitude inherent in language cannot be seen in isolation from the cultural context in which the translator is working, whether alone or in collaboration with others. Therefore, it is a myth that translators can convey the text impartially without adding individual ideology, beliefs and values in the translation process. In this context, as Tymozcko points out, rather than seeing translators as simply an intermediary who transmits linguistically, removed from all influences, it is much more realistic to see them as individuals under the influence of both their own culture, and also of dominant ideological, linguistic and cultural factors. With every decision taken, certain ideological choices are made in terms of worldview, belief, way of thinking and values, although not necessarily in a direct political sense. The most obvious indications that these choices are of an ideological nature emerge by comparing different versions of a translation of a source text. These indicators are generally heard as the voice of the translators themselves, but also as the voice of the patrons, who impose limitations on the translators, and also the target society and culture. In fact, translations can be thought of as "mixed" texts, a blend of all these sounds, each of which is heard in different tones and strengths in different parts of the text. In this respect, translation is one of the most effective tools for the exploration of the individual and society, at both the linguistic and cultural levels.

\section{Giriş}

Çeviri edimi ve olgusunun dilsel/metinsel ya da iletişimsel bir aktarıma indirgenemeyeceği, günümüzde çevirinin toplumdaki işlevi konusunda araştırma yapanlar tarafından kabul edilmektedir. Çünkü çevirinin salt dilsel, kültürel, düşünsel bir edim olmayıp, toplumları oluşturan inanç, yaşam, ekonomi ve değerler dizgesi gibi farklı alanları etkileyip değiştirdiği ya da biçimlendirdiği, çeviriye ilişkin yapılan kuramsal ve tarihsel çalışmalarda dile getirilmektedir. Dolayısıyla çeviri olgusunu tek düzlemli bir aktarım olarak ele almak, onun karmaşık ve zaman/uzama bağlı görece bir güç aracına dönüşebileceğini göz ardı etmek anlamına gelmektedir. Tarih boyunca toplumların gelişim ve değişiminde önemli bir rol oynayan dini, siyasi, felsefi ve bilimsel metinlerin oluşmasında ya da ortaya çıkmasında çevirilerin etkisi düşünüldüğünden fazladır. Toplumsal ve kültürel tarihi belirleyen düşüncelerin gelişmesinde olduğu kadar, toplumların birbirini olumlu ya da olumsuz anlamda etkilemesinde çevirinin belirleyici bir yeri vardır. Bunun nedeni, metinlerin/ çevirilerin toplumları biçimlendirmede en etkili araçlardan biri olmasıdır. Genel anlamda, 
salt toplumunda yaşayan birey ve kurumlar tarafından metinler oluşturulsa da, başka dil ve kültürden çeviri yoluyla aktarılan yeni metinler topluma kazandırılmaktadır. Ancak bu kazanç, her zaman toplumun yararına olacağı anlamına gelmemektedir. Burada çevirilerin kimler tarafından, neden ve hangi hedefe ulaşmak için yapıldığına bakıp çevirilerin hangi amaçla kullanılmak istendiği sorgulanmalıdır. Belli bir amaç ve niyetle yapılan bir edim, çeviride olduğu gibi, ideolojik bir araca dönüşebilmektedir. Çünkü ideoloji kavramına, Thompson'un İdeoloji ve Modern Kültür adlı kitabında vurguladığı gibi, sosyal bilimlerin kullandığı betimleyici kavramlar bağlamında ele alınıp tarafsız ideolojik düşünce biçimi olarak 'toplumsal eylem ya da siyasi pratiğe mahsus 'düşünce sistemleri', 'inanç sistemleri' veya 'sembolik sistemler' gözüyle” bakılabilir (2013: 14). Söz konusu olan bu sistemler/dizgeler, birbirinden soyutlanarak kapalı bir alan olarak yorumlanamaz. Eylem, düşünce ve inançları etkileyen ya da bunları değiştirmeye çalışan ürünlerden biri de, hiç kuşkusuz başka bir dil ve kültürden aktarılan çevirilerdir. Bu açıdan bakıldığında, çeviriler bir toplumda ya da kültürde algı yönetimini biçimlendirmede etkili bir araca dönüşebilmektedir. Çeviri denilen ürünler, belli bir zaman ve uzamda bir güç odağ 1 tarafından planlı ve kasıtlı belli bir etki yaratarak, toplumu değiştirmeye ya da yönlendirmeye çalışıyorsa, ideolojik bir yaklaşımdan söz edilebilir. Bazen bu tür yaklaşımlar, toplumun gelişimi için gereksinim duyacağı yeni alan ve düşüncelerin ortaya çıkması ya da kendini sorgulaması için de kullanılmıştır. Çevirilerin, kaynak kültürdeki diğer metinlerden önemli bir farkı, bu tür metinlerin farklı bir toplumda belli bir etki yapması amacıyla görece olarak 'kısa' bir sürede erek kültüre aktarılabilmesidir. Başka bir anlatımla, bir kaynak metnin çevrilmek üzere seçilirken, bunun erek kültürde yaratacağı olası etkiler düşünülmektedir. Erek kültür açısından değerlendirildiğinde, zamanla etkisi ve işlevi ortaya çıkacak 'yeni' bir yapıt ortaya koymaktansa, etkisi ve işlevi başka bir toplum ve kültürde görülmüş bir yapıtı çeviri yoluyla aktarmak, erek kültür için bir kazanım olarak yorumlanabilir. Dolayısıyla, bir metnin çevrilmesi için gerek seçilmesi ve başka bir dile ve kültüre aktarılması, gerekse çevirinin işlevinin belirlenmesi bakımından toplumda belli bir gereksinimi giderebilmesi onun son derece karmaşık ve etkili bir araç olduğunu ortaya koymaktadır. Tahir-Gürçağlar'ın da haklı olarak altını çizdiği gibi, çevirinin ideolojik bir aktarım olarak bir ülkenin yazın ve kültür dizgesini biçimlendirmedeki etkisi son yıllarda üzerinde durulan konulardan biri olması, çevirinin ideolojiden ayrı bir olgu olarak düşünülemez olduğunu yansıtmaktadır (2014: 113).

Bu çalışmada, çeviribilim alanında ideoloji kavramının nasıl tartışıldığı, çeviri sürecinde alınan kararlarda ideolojinin hangi bakımdan yönlendirici bir etkiye sahip olduğu ele alınacaktır. Bu bağlamda, bu kararların alınmasında hangi etmenlerin belirleyici olduğu, alınan kararlarda kimlerin etkili olduğu, bu kararlara göre çevirilerin nasıl değişebileceği gibi sorulara yanıtlar aranacaktır. Bütün bu soruları yanıtlayabilmek için öncelikle ideoloji kavramının açılımı ve anlamı irdelenecek, daha sonra ideoloji kavramın hayatın farklı alanlarını etkileyen bir araç olarak algılanmayıp salt siyasi anlamda yorumlanmasının dar bir kavram olarak ele alınamayacağı ortaya konacaktır. 


\section{İdeoloji kavramının anlamı ve nitelikleri}

İdeoloji sözcüğünün kökenine baktığımızda, sözcüğün Türkçeye Fransızca "idéologie"den geldiği görülmektedir. Grekçe "Eidos" ve "logos" sözcüklerinin bir araya gelmesiyle oluşan ideoloji kavramı, "fikirlerin bilimi" anlamına gelmektedir (Aslan, 2004: 11). İdeoloji kavramı ilk kez A. Destutt de Tracy tarafindan idealar bilimi anlamıyla kullanılmıştır (Fawcet ve Munday, 2009: 137). ${ }^{1}$ Ancak kavramın on sekizinci yüzyıl sonlarında Fransa'da ortaya çıktı̆̆ görülmektedir (Thompson 2013: 10). Türk Dil Kurumu, ideolojiyi "siyasal veya toplumsal bir öğreti oluşturan, bir hükûmetin, bir partinin, bir grubun davranışlarına yön veren politik, hukuki, bilimsel, felsefi, dinî, moral, estetik düşünceler bütünü" (TDK, 1998: 1047) olarak tanımlamaktadır. Larrain, ideoloji kavramının, öncelikle burjuvazinin feodaliteye karşı verdiği ilk mücadeleler sırasında geleneksel aristokrat toplumda ortaya çıktığını ve on sekizinci yüzyıl aydınlanmacılığının felsefe ve kültür ortamında üretildiğini belirtmektedir; o dönemde Aydınlanma filozofları, gerçeğe ancak akılcı ve bilimsel bir yoldan ulaşılabileceğini, bu şekilde toplumun akılcı olarak yeniden yapılandırılabileceğini belirtmektedir. (Larrain, 1994: 9). Tarihsel bağlam içinde ideolojinin, akla derin inancı talep eden bir düşünceler bilimi ve eski düzene karşı verilen mücadelede kullanılan eleştirel bir silah anlamlarını içerdiği ileri sürülmektedir (Larrain, 1994: 9-11). Alanyazın incelendiğinde, ideoloji ile ilgili tanımların Marx'la birlikte farklılaştığı görülmektedir. İdeolojiyi altyapının bağımlı değişkeni olarak gören Marx’a göre ideoloji, Lefebre'nin altını çizdiği gibi “dünyayı nasıl görmek gerektiğini belirtirken yaşam biçiminin de yorumlanmasını sağlar, (...) kendini haklı görmek isteyen egemen oluşumuna yardım eder. O bir dünya görüşüdür ya da dünya görüşünü temsil eder" (akt. Kazanc1, 2006: 71). ${ }^{2}$

Terry Eagleton'a göre ideolojinin işlevi toplumdaki yöneten sınıfin gücünü meşrulaştırmaktır; topluma egemen görüşler, yöneten sınıfın görüşleridir (1981: 14). Bu açıdan bakıldığında ideoloji, sınıflı toplumlarda insanların kendilerine düşen rolleri yaşama tarzlarını, onları toplumsal işlevlerine bağlayan ve böylece toplumun bütünü hakkında doğru bilgi edinmelerini önleyen değer, düşünce ve imgelerdir (Eagleton, 1981: 28). Eagleton İdeoloji adlı kitabında ideoloji kavramının ne kadar geniş olduğunu ve farklı açıdan irdelenebileceğini vurgulamak için ideolojinin on altı maddeden oluşan tanımlarından söz etmektedir: 1. toplumsal yaşamdaki anlam, gösterge ve değerlerin üretim süreci; 2. belirli bir toplumsal grup veya sınıfa ait fikirler kümesi; 3 . bir egemen siyasi iktidarı meşrulaştırmaya yarayan fikirler; 4. bir egemen siyasi iktidarı meşrulaştırmaya hizmet eden yanlış fikirler; 5. sistemli bir şekilde çarpitılan iletişim; 6. özneye belirli bir konum sunan şey; 7. toplumsal çıkarlar tarafindan güdülenen düşünme biçimleri; 8. özdeşlik düşüncesi 9. toplumsal olarak zorunlu yanılsama; 10. söylem ve iktidar konjonktürü; 11. içinde, bilinçli toplumsal aktörlerin kendi dünyalarına anlam verdikleri ortam; 12. eylem-amaçlı inançlar kümesi; 13. dilsel ve olgusal gerçekliğin karıştırılması; 14. anlamsal [semiotik] kapanım; 15. içinde, bireylerin, toplumsal yapıyla olan ilişkilerini yaşadıkları kaçınılmaz ortam; 16. toplumsal yaşamın doğal gerçekliğe dönüştürüldüğü süreç (Eagleton, 1996: 18). Bu tanımlamalardan yola çıkan Eagleton, ideolojinin altı farklı şekilde tanımlanabileceğini belirtmektedir: 1. toplumsal yaşamdaki fikir, inanç ve değerleri üreten maddi süreç; 2 . toplumsal açıdan önem taşıyan belli bir grubun 
veya sınıfın içinde bulunduğu durumu ve yaşam deneyimlerini simgeleyen inanç ve fikirler; 3. çıkar çatışması durumunda toplumsal grupların çıkarlarının meşrulaştırılması ve desteklenmesi; 4. egemen grubun veya sınıfin içinde bulunduğu durumu ve yaşam deneyimlerini simgeleyen inanç ve fikirler; 5. yönetici bir grup ya da sınıfın çıkarlarını, çarpıtma ya da saklama yoluyla meşrulaştırmaya yardımcı olan fikir ve inançlar; 6. yanlış ve aldatıcı inançlar (Eagleton, 1996: 29-30).

İdeolojiyi kültürel bağlamda ele alan Louis Althusser, ideolojinin yapının özne üzerindeki etkisi olduğunu ve yaşamın içinde oluşan bir uygulama olduğunu öne sürmektedir (1970: 121). Bundan dolayı ideolojiler, bireylere hakimiyet ve iktidar kavramlarını benimseterek, yaşadıkları sisteme uyumlu hale gelmelerini ya da kendilerine ait yeni bir yaşam dizgesi kurmalarını sağlamaktadır. Bu da ideolojinin soyut bir kavram olarak değil; maddi bir kavram olarak görülmesine neden olmaktadır (Althusser, 1970: 121). İdeolojileri sosyal gruplarca paylaşılan özel bir sosyal biliş biçimi olarak tanımlayan Teun A. van Dijk'a göre ideolojiler, grup üyelerinin, aynı zamanda ideolojik üretim, yeniden üretim ve güçlük olarak da kendini gösteren söylemlerinin de içinde bulunduğu sosyal temsillerin ve uygulamaların temelini oluşturmaktadır (2001: 12). Bundan dolayı van Dijk ideolojiyi söylemden ayırmayarak bir toplumsal grup tarafindan paylaşılan ideolojinin, bireylerin konuşmalarını ve yarattıkları metinleri de etkilediğine işaret etmektedir (1998: 13). Aynı grubun üyeleri olan insanlar, ideolojilerini öğrenmek, onaylamak, söylemek ve diğer üyelerle paylaşmak için dili kullanırlar, benzer şekilde, ideolojilerini dışarıya karşı savunmak ve yaymak için de en etkili aracın dil olduğunu savunmaktadır (van Dijk, 1998: 13). 1990'lı yıllarda ideoloji ile dil arasında van Dijk gibi benzer ilişki kuran Fairclough ideolojiyi, söylem çözümlemesi bağlamında tartışarak ve dilbilimsel açıdan toplumsal ilişkileri sorgulayarak, iktidar/gücün dili nasıl belirlediğini ortaya koymuştur (1995: 78). ${ }^{3}$ Christina Schäffner'ın da, ideolojinin çalışma alanının büyük ölçüde dil ve dil kullanımı olduğunu vurgulaması (1996: 5) ideolojilerin dili ve dolayısıyla düşünce yapılarını nasıl belirlediğini göstermektedir. Kullanılan dile bu açıdan bakıldığında çevirinin toplumda egemen olan ideolojiyi ortaya koymak için somut bir gösterge niteliği taşıdığı söylenebilir. İdeolojinin çeviriye nasıl yansıdığı ve ideoloji ile çeviri arasında nasıl bir ilişki olabileceği kuramsal düzlemde irdelenmelidir. Bu bölümde kavramsal tartışmalar ve öne sürülen görüşler çeviri edimi ve olgusu açısından ilişkilendirilebilir. Çünkü çeviride, giriş bölümünde de işaret edildiği gibi, ‘özgün' metinlerden farklı olarak bir tercih yapma, bir işverene bağll1ıktan dolayı bir yönlendirme ve bir toplumun gereksinmelerini karşılamaya ilişkin beklentiler söz konusudur.

\section{İdeoloji ve çeviri ilişsisi}

Dilin yaratıcılığı da kapsayan bir etkinlik ${ }^{4}$ olarak değerlendiren Humboldt'a göre dil, salt sözcüklerin bir araya getirilmesinden oluşan bir yapı olmanın ötesinde düşünce üretme ve kavram kurma sürecine katılan biçimlendirici bir etkinliktir (Humboldt, 1988: 51). "Her dil bir dünya görüşüdür" savından yola çıkan Humboldt'a göre "bir ulusun dili o ulusun dünya görüşünden bağımsız olamaz. Bu dünya görüşü, dili belirler ve geliştirir (Akarsu, 
1998: 42). Dolayısıyla “düşünceler, dili yarattı̆ğ gibi, diller de düşünceleri yaratırlar (1998: 43) $\mathrm{Bu}$ açıdan bakıldığında, kültürler arası farklılıklar dile yansıyacağından bir sözcügün ya da kavramın başka bir dilde eşdeğeri olması olanaksızdır. Çevrilemezlik anlayışının bir sonucu olan bu görüş, kültüre göre değişen diller arasındaki yapısal ve biçimsel farklarla eşdeğer bir anlamın başka bir dilde yaratılamayacağına işaret etmektedir. Bu nedenle, dil, kültür/ruh ve düşüncenin bir bütün olduğunu savunan Herder, Humboldt ve Schleiermacher gibi düşünürler çevrilemezlik anlayışını ileri sürmüşlerdir. ${ }^{5}$ Dilin düşünceyi, düşüncenin de dili belirlediği savından yola çıkıldığında, bir düşüncenin belli amaçlar doğrultusunda başka bir kültüre ve dile aktarılması, aynı zamanda dilin buna uygun biçimde değiştirilmesi olarak yorumlanabilir. Daha açık bir deyişle, insanların başkalarının düşüncelerini etkilemek ya da değiştirmek için dili, dolayısıyla da çeviriyi bir araç olarak kullanması, onun ideolojik bir araca dönüştürülmesine yol açacaktır. Burada düşünceleri etkilemek ve biçimlendirmek için belli yapıtların, yazarların ve konuların seçimi kadar çeviride nasıl bir strateji izleneceği de belirleyici bir etmen olabilir. Çünkü bir yapıtın bir dilden başka bir dile aktarımı ve bir karar alma süreci olan çeviri süreci, karar vericinin ideolojisini de içinde barındırdığı gibi, dili kullanım biçimini, ideolojik amaç ve görüşlerle yönlendirilmediğinde bile yeterince ideolojik bir davranışa işaret etmektedir (Kanca, 2009: 77). Bu çerçevede, her çeviride, bilinçli ya da bilinçsiz olarak ideolojik bazı tercihlerin yapıldığı ve kararların kaçınılmaz biçimde alındığı söylenebilir. Söz gelimi, bir metni bir dilden diğerine aktaran çevirmen, bazı kişisel, sosyal, kültürel, entelektüel ve ideolojik etmenlerden etkilenmektedir. Bu bağlamda, kaynak metnin okuru ve erek metnin yazarı olan çevirmen, bu etmenlerin doğrudan ya da dolaylı olarak etkisi altında kalarak erek metni oluştururken, anlam kaymaları, kelime seçimleri, eklemeler, çıkarmalar, anlam daralmaları veya genişlemelerine yol açan bazı kararlar alabilmektedir. Çeviride, metin seçimi ve çeviri stratejisinin yanında erek dilde içerik oluşturma süreci metnin ideolojisini yansıtan etmenlerdendir. Schäffner'in öne sürdüğü gibi ideolojik yönlerin gerek metin içinde, gerek sözcük, gerekse dilbilgisi düzeyinde saptanması söz konusudur. Örneğin, sözcük düzeyinde, bazı sözcüklerin bilinçli biçimde seçilmesi ya da bazı sözcüklerin kullanılmama tercihi; dilbilgisi açısından ise fiili yapan özneyi gizlemek için edilgen yapıların kullanılması, belli ideolojilerin yansıtılması açısından çeviride sıkça karşılaşılan durumlardır (Schäffner, 2014: 23).

Kuramsal olarak güç kavramını irdeleyen çeviri bilimcilerden André Lefevere ve Susan Bassnett, her ne kadar çeviri çalışmalarında tümceden metin düzeyine çıkılmış olsa da, çeviri araştırmalarında metnin ötesine geçilmediğini, çevirinin salt dilbilimsel bir yaklaşımla anlaşılamayacağını, çeviride bağlamsal ve tarihsel boyutun göz önünde bulundurulması gerektiğini vurgulamaktadırlar (1990: 4-11). Çünkü çeviriler, dilbilimsel çözümlemelerin ötesinde, kültürü de kapsayan karmaşık ve çok düzlemli bir olgudur (Lefevere Bassnett, 1990: 12). Bu nedenle çeviriler, Lefevere ve Bassnett'e göre hiçbir zaman, iktidar, güç, kültür gibi değişkenlerden soyutlanamaz (1990: 7). Bundan dolayı, çeviri anlayışındaki değişimi ya da başka bir deyişle çevirideki evrimi 'kültürel dönüş' (cultural turn) olarak tanımlayan araştırmacılar, bir yandan çevrilecek yapıtın nasıl seçildiği, öte yandan ise çeviri sürecinde çevirmenin, haminin, editörün ya da yayımcının rolü, çevirmenin süreç boyunca başvuracağı stratejilerin 
belirlenmesi ve çevirinin erek dizge tarafından nasıl kabul edileceği gibi farklı yönlendirmelerin etkisi altında gerçekleşen karmaşık süreçlerin ancak çevirinin ve çeviri sürecinin irdelenmesiyle anlaşılabileceği görüşündeler (1990: 123).

Lefevere, 1992 yılında yayımlanan Translation, Rewriting and the Manipulation of Literary Fame adlı kitabında çeviriyi patronaj, ideoloji, yazın kuralları ve anlam evreni çerçevesinde gerçekleştirilen en önemli yeniden yazım (rewriting) örneklerinden biri olarak göstermektedir. Bu bağlamda, Lefevere'e göre her yeniden yazım (ve dolayısıyla çeviri de) belli bir ideolojiyi ve yazın kurallarını temsil ettiğinden yazını manipüle etmektedir. Bu nedenle, "yeniden yazım, güce ve iktidara hizmet edecek biçimde bir manipülasyon"“6 (1992: vii) olarak değerlendirilmektedir. Diğer metinlerle karşılaştırıldığında çevirinin, yeniden yazma işleminin uygulandığı en popüler ve potansiyel açıdan en etkili olan metin olmasının nedeni, Lefevere'in altını çizdiği gibi, kaynak metin yazarının düşüncelerinin bir başka kültüre (erek kültüre) taşınarak, ilk ortaya çıktığı kültürle olan sınırlarının ortadan kaldırılmasıdır (1992: 9). Yeniden yazılmış metinler (yani çeviriler), belli bir gruba hizmet ettiklerinden dolayı önemli bir işlevi de yerine getirmektedirler. Bu metinler, ya egemen ideolojinin çıkarlarına uygun ya da tam tersi ona aykırı bir yol izleyebilmektedir (Lefevere, 1992: 7). Bunun yanında, etkili bir araç olarak toplumun yapısını ve görüşlerini koruyan bir güç etmeni olarak ya toplumu köklü bir değişikliğe uğratabilecek ya da mevcut düşünceleri derinden sarsabilecek manipülasyon gücüne sahiptir. Bazen metinleri yeniden yazanlar, çeviri aşamasında kaynak metni, çağın egemen ideolojik ya da diğer akımlarına uygun bir biçimde adapte veya manipüle ederler ${ }^{7}$ (Lefevere, 1992: 8). Yeniden yazma sürecinde çevirmenin nasıl bir kimliğe sahip olduğu ve ideolojik amacı doğrultusunda kullanacağı çeviri stratejileri hiç kuşkusuz önemli bir yere sahiptir. Bu açıdan bakıldığında, çevirmen yeniden yazım sürecinde kaynak metinde kendi ya da hamisinin görüşüyle uyumlu olan ve onlarla çatışmayan niteliklerin olumlu yönlerini ön plana çıkaracaktır ya da görüşüne/inancına aykırı gelen olumsuz yönlerini vurgulayarak, baskın ya da karşıt olan ideolojileri karşı karşıya getirecektir (Lefevere, 1992: 14). Buna karşın çevirmenler, kaynak ve erek metin arasında etkili bir iletişim için kaynak metnin ideolojik yönlerini ön plan çıkarmak yerine, erek okuyucunun beklentisine/ideolojisine uygun biçimde "yeniden yazım” yapmalıdır. Bu anlayışı benimseyecek olan bir çevirmen, metnin okur tarafından alımlanmasını kolaylaştırarak erek okuyucu üzerinde güçlü bir etki yaratabilir. Bunun sonucunda çevirmen, istenilen iletinin adresine ulaşmasını sağlayarak dolaylı olarak ideolojik etkiyi arttırabilir (Lefevere, 1992: 19). Lefevere, burada çevirinin yerelleştirilerek ve çevirmenin bir anlamda görünmez kılınarak okuyucunun, çevirinin yabancılığını fark etmeden sanki çeviri kendi kültürünün bir ürünüymüş gibi ondan daha kolay etkilenebileceği görüşünü dile getirmektedir. Çünkü çevirinin kolay alımlanması, Venuti’nin deyişiyle daha akıcı biçimde okunmas $1{ }^{8}$ çeviriyi araçsallaştırdığı gibi çevirinin doğasından kaynaklanan yabancılığını yok etmektedir ve onu bir anlamda kolay tüketilebilir kılmaktadır. Yeniden yazma sürecinde, çevirmenin ideolojisini yansıtan çeviri kararları, mesleki etiği ya da benimsediği dünya görüşü, hami tarafindan çevirmene doğrudan ya da dolaylı biçimde dayatılan ideolojik tercihler ya iki tarafın, genellikle haminin lehine uzlaşmasına ya da tam tersi, çevirmenin direnç göstermesiyle hami ile karşı karşıya kalmasına yol açacaktır. 
Yeniden yazma sürecinde "hamilik" (patronage) kavramını ve hamiliğin çeviri üzerindeki etkisini daha ayrıntılı biçimde sorgulamadan önce, yapısalcı dilbilimsel yaklaşımlarda ve betimleyici çeviribilimciler tarafından savunulan dizge kavramının Lefevere'de nasıl yorumladığını açıklamakta yarar vardır. Çeviri kuramlarında ele alınan dizge kavramı, toplumu biçimlendiren farklı etmenler üzerinde ideolojinin nasıl bir etki bırakabileceği ve dizgeler arasındaki ilişkinin gereksinmelere göre nasıl değişebileceğini göstermesi açısından önemlidir. Aksoy’un öne sürdüğü gibi, Lefevere

\footnotetext{
“kendi dizgeler kavramını, Even-Zohar'ın kavramından farklı içerikte ele almış ve çeviri sürecini ve toplumu oluşturan dizgelerin hamilik, ideoloji, yazın kuralları ve söylem evreninden oluştuğunu belirtmiştir. Lefevere [ayrıca], dizge ve çevre arasındaki etkileşimi, dizgenin iç düzenini ve denetim unsurlarını vurgular" (2002: 50).
}

Lefevere'e göre yazın karmaşık bir toplumsal dizgedir ve toplumdaki diğer dizgelerin üstlenemeyeceği işlevleri yerine getiren kendine özgü bir yapısı vardır (1992: 12-13). Dizge gerek okuyucu, gerekse yazar ve yeniden yazanlar üzerinde bir dizi kısıtlamalar/sınırlamalar getirerek metinlerin nasıl çevrilmesi ya da okunması gerektiğini belirlemektedir. Metinleri yeniden yazan çevirmenler, dizgeye ve onun getirdiği kısıtlamalara uyabileceği gibi bunlara karşı gelecek dizgenin dışına da çıkabilir. Lefevere, yazın dizgesinde iki denetim mekanizmasının bulunduğundan söz etmektedir: İlk mekanizmada, yazın dizgesini içeriden denetleyen eleştirmen, öğretmen ve çevirmenler gibi profesyonellerden oluşmaktadır. İkinci denetim mekanizması ise, yazın dizgesinin dışında bulunan ve hami tarafından idare edilen ve bir grup insan, hükümet, askeri bir cunta, dini bir kurum, siyasi bir parti, toplumsal bir sınıf, yayın evleri, medya gibi hamiliklerden oluşmaktadır (1992: 14-15). Ancak, Lefevere, bir toplumda ideolojinin tek kutuplu olamayacağını vurgulamaktadır, merkez ve çevre ${ }^{9}$ olarak nitelendirilen ideolojiler arasında bir mücadele vardır ve ikisi de birbirinin yerini almaya çalışmaktadır. Lefevere, alana göre çeviriyi ve çevirmeni farklı biçimde etkileyen hamiliği üç gruba ayırmaktadır: ideolojik, ekonomik ve statü. Çevirmene hamileri tarafından dayatılan veya çevirmenin bizzat sahip olduğu ideolojik görüş, çevrilecek konunun seçimini ve nasıl çevrilmesi gerektiğini belirlemekte rol oynamaktadır (Lefevere: 1992: 86). Burada özellikle ideoloji, ekonomi ve statüyü belirleyen hamilere işaret edilmesi, çeviri olgusunun ve sürecinin salt çevirmene bağlı olmadığ verenlerin bazı beklentilerinin olduğu ve çeviriye ilişkin yapılacak değerlendirmelerin ve eleştirilerin yalnızca çevirmene yönelik görülmemesi gerektiği yaklaşımı ön plana çıkmaktadır. Başka bir deyişle, çeviride alınan kararların ya da çeviride yapılan farklı tercihlerin sorumluluğu salt çevirmene yüklenemez. Bazen bu karar ve tercihler, çevirmenin isteği dışında ya da çeviri sonrası süreçte işverenin/haminin isteği doğrultusunda yapılacak müdahaleler yoluyla alınabilmektedir.

Basil Hatim ve Ian Mason, salt politik eylem ve düşüncelerin ‘ideolojik’ olarak tanımlanmaması gerektiğini, dilin tüm kullanım biçimlerinin, dili kullananların yaklaşım, inanç ve değer dizgeleri ile oluşturdukları bakış açılarını yansıttığını dile getirmektedirler. Kurumsallaşmış olan konuşma ve yazmanın niteliklerinin, söylemi ifade etmesi açısından ideoloji 
kavramıyla birlikte değerlendirmenin yararlı olacağını vurgulamaktadırlar (1997: 120). Bu bağlamda, yerleşik ve gelenekselleşmiş olan bazı ifade, kalıp ve söylemlerin benimsenen ideolojiyi etkileyebileceği söylenebilir. Çünkü bu tür kullanımların daha kolay kabul görmesi, bazen ideolojilerin bunlardan yararlanması ya da bunları olumlu ya da olumsuz anlamda kullanması söz konusudur. Söz gelimi, kendi görüşlerini çeviri aracılığıyla yaymak ya da okurları daha fazla etkileyebilmek için egemen ideolojinin söylemleri kullanılabilir. Çevirmenin/haminin kaynak metinde kullanılan alışılmadık/yenilikçi bir dili ya da değerlerine ters gelen bazı inanışları, çeviride alışıldık/bilinen bir dile ya da yaygın inanç normlarına uygun biçimde değiştirmesiyle, eleştirel bir tutum ve dile sahip bir çeviri metni birdenbire, çeviri yoluyla gelenekseli önceleyen ve tutucu bir dile sahip bir yapıta dönüşebilir.

Mason, ideolojiyi, bir bireyin veya kurumun dünya görüşünü yansıtmakla beraber olay, gerçek ve deneyimlerin farklı yönlerini yorumlamaya yardımcı olan inançlar ve değerler kümesi olarak tanımlamaktadır (2012: 83). Bu bağlamda, Meksika tarihi ve çevirisi ile ilgili bir metinde kullanılan dildeki sistematik ideolojik değişimlerin izlerini araştırarak ideolojinin çeviri seçimlerini fark ettirmeden (bilinçaltının da kullanılmasıyla) nasıl etkilediğini göstermeye çalışmaktadır. Mason, ideoloji ve ideolojik çarpıklık üzerine yoğunlaşmasına karşın, hepimizin çevremizde egemen olan söylemler tarafından kısıtlandığı ve bu nedenle hedef metnin farklı bir şekilde gerçekleşen söylemini, çevirmenin niyetiyle ilişkilendirmeye gerek olmadığını varsayar (2012: 83). Yazınsal metinlerin yaratıcı boyutunu bir okur olarak alımlayıp, bir profesyonel olarak başka bir dile ve dolayısıyla kültüre aktaran çevirmenlerin çeviri sürecinde alacakları kararlarda ve yayınevlerinin kaynak metnin seçiminde ve elden geçirilmesinde kendilerini ideolojiden soyutlanmalarını beklemek gerçekçi bir yaklaşım olamaz. Çünkü karmaşık bir niteliğe sahip olan dil, Bulut'un da işaret ettiği gibi bireysel bir olgu olmakla birlikte ideolojik bir kavramdır (2008: 43). Çeviride kullanılan dil, kaynak metinden farklı olduğundan ya da eşdeğer anlamda aynı olamayacağından çeviride ideolojinin daha belirgin biçimde metne yansıdığı söylenebilir. Her ne kadar yazarın kullandığı dilin ve betimlediği dünyanın ideolojik bir tercihe ve seçime bağlı olsa da, çeviride kaynak metne göre "doğal bir süreç" söz konusu olmadığından müdahaleler, kısıtlamalar ve yönlendirmeler daha fazladır. Bundan dolayı Jeremy Munday Translation and Ideology adlı çalışmasında haklı olarak belirttiği gibi, çevirinin ideolojik boyutu genellikle olumsuz yan anlamıyla anılmakta, ideoloji, çeviriyi bir yönlendirme (manipulation), bozma (distortion) ya da yeniden yazım (rewriting) işlemine dönüştürmektedir (2007: 195-217).

\section{Çevirmen ve ideoloji}

Basil Hatim ve Ian Mason 1990 yılında kaleme ald1kları Discourse and the Translator adlı kitaplarında çevirmeni, devingen bir süreç olan çeviri ediminin merkezinde yer alan ve kaynak metnin üreticisiyle metnin erek alıcıları arasında aracı konumda olan biri olarak tanımlamaktadır (1990: 223). Kültürler arasında olduğu kadar kültür bağlamındaki ideolojiler, ahlak dizgeleri ve sosyo-politik yapılar arasında bir aracılık görevi üstlenen çevirmenlerin, kültürler arasındaki farklılıkları görüp bunları aktarabilecek vizyona sahip olması gerektiğini vurgulayan kuramcılar, çevirmenlerin aynı zamanda kaynak metinlerin ilk okurları olduğunu 
ve sıradan bir okurdan farklı olarak alımladıkları kaynak metni bireysel ideoloji, inanç ve değerlerini çeviriye katmadan olabildiğinde tarafsız biçimde aktarmakla sorumlu olduklarını belirtmektedirler (Hatim ve Mason, 1990: 223, 224). Burada geçen "tarafsızlık" kavramının göreceli olduğu ve kime karşı tarafsız olduğu tartışmalı bir konudur. Çevirmenin de her okur gibi erek kültür ve toplumun bir parçası olduğu düşünüldüğümde, çeviride alacağı kararlarda erek okuru da hesaba katması kaçınılmazdır. Çünkü çevirinin okurunun değişmesi, beklentilerin, alımlamanın, değerlerin ve bakış açısının değişmesi anlamına gelmektedir. Kaynak metni "tarafsız" bir biçimde aktarması beklenen çevirmen, değişen bu etmenleri salt kaynak metne bağlı kalarak göz ardı edebilir mi? Konuya bu çerçevede bakıldığında, "tarafsızlık" yerine "bağlılık" kavramının kullanılması daha uygun olacaktır. Burada da haklı olarak kime karşı "bağlılık" sorunu sorulabilir. Yazara mı, okura mı, işverene mi, kendi yaklaşımına mı yoksa içinde yaşadığı toplumun gerçeklerine mi bağlılık sorusu önem kazanmaktadır. Özellikle üslubun, anlatım biçiminin, dili yaratıcı biçimde kullanmanın ve estetik etkinin belirleyici olduğu yazınsal metinlerde işlevsel çeviri yaklaşımını destekleyen Nord'un gerek kaynak metin yazarına, gerekse erek metnin okuruna bağlılık anlamında kullandığı "Loyalitaet” (2003: 31) kavramının kullanılması daha uygun bir tercih olacaktır. Çünkü çevirmenin tarafsız olması düşünülemez ama bir yere ya şeye bağlı olması, daha gerçekçi ve açıklanabilir bir durumdur.

Maria Tymoczko'nun Ideology and Translator - In What Sense a Translator is 'In Between'? başlıklı makalesi, çevirmenin "arada olma/bulunma"10 konumuna işaret ederek çevirmen ve ideoloji arasındaki ilişkiyi sorgulaması açısından dikkate değerdir. İdeolojik etkinin her çeviriye göre, dahası aynı metnin farklı çevirilerinde bile değişebileceğini, çünkü ideolojinin salt çevrilen metnin değil, çevirmenin sesi ve duruşuyla birlikte metnin alıcı kitlesinin de bir parçası olduğunu savunan Tymoczko, ideolojinin çevirmene bağlı olan değişkenlerinin, çevirmenin süreçteki konumuyla doğrudan ilintili olduğunu belirtmektedir (2014: 181). “Çevirmenin sesi” Hermans'a göre, kaynak metindeki sesten farklı olarak çeviride ikinci ses olarak çevirmenin söylemsel varlığının bir göstergesidir. Bu ses, tamamen anlatıcının arkasına gizlenebileceği gibi, bazen de metin dışı bir çeviri notuyla konuşan özneyi niteleyen türden kendine bir gönderme yapmaktadır (1997: 65). Çevirmenin genellikle kaynak kültür ve erek kültür 'arasında' konumlandırıldığının altını çizen Tymoczko, çevirinin sosyal, kültürel ve ideolojik bağlamda da incelenmeye başladığı son zamanlarda çevirmenin konumunun yeniden değerlendirilmesi gerektiğini öne sürmektedir. Ona göre kültür etkileşiminin bu denli yoğun olduğu bir çağda, hele de bireysel inanç ve değerleri de işin içine girince, çevirmenin iki kültürün de dışında kalan bir aralıkta yer almasına imkân yoktur. Bir kültüre ait olmakla birlikte, farklı kültürlerle de etkileşimde olan çevirmen, çeviri sürecinde erek ve kaynak kültür dizgelerini bir araya getirerek kendisini bu yeni ve geniş alanda konumlandırmaktadır (Tymoczko, 2014: 182-183). Bu açıdan bakıldığında, çevirmenin, her tür ideolojik, dilsel ve kültürel etkiden soyutlanmış bir alanda dilsel aktarım yapan bir aracıdan çok, gerek kendi kültürünün gerekse baskın ideolojik, dilsel ve kültürel etmenlerin etkisi altında kalan bir birey olarak görüldüğü söylenebilir. Çevirmen, profesyonel olarak çeviri işi yapsa da, belli bir toplumun üyesi olan 
her insan gibi ideolojik etkilere açık bir bireydir. Bu da onun, erek ve kaynak dizgeler 'arasında' bulunan tarafsız alanda yer almasını olanaksız kılmaktadır. Söz konusu bu alan, her ne kadar farklı olsa da, tarafsız olması düşünülemez. Kendisinin ya da çeviri sürecini etkileyen başka insanların kararına ve tercihlerine göre bir tarafa daha yakın ya da uzak kalması kaçınılmaz olacaktır.

\section{Sonuç}

Çeviri, yazın ve kültür dizgesini biçimlendirirken ideolojiden bağımsız düşünülemez, buna bağlı olarak, dilin kullanımı kendine özgü bir işleve doğru gelişim gösterir ve toplumsal normlara/beklentilere göre biçimlenir. Dilin doğasında var olan bu ideolojik tutum çevirmenin tek başına ya da ortak olarak aldığı kararlarla, içinde bulunduğu kültürden soyutlanamaz. Dolayısıyla çevirmenlerin çeviri sürecinde metni, bireysel ideoloji, inanç ve değerlerini katmadan tarafsız bir şekilde aktarması söz konusu değildir. Bu bağlamda Tymozcko'nun işaret ettiği gibi, çevirmeni her tür ideolojik, dilsel ve kültürel etkiden uzak bir alanda bir başına dilsel aktarım yapan bir aracıdan çok, gerek kendi kültürünün gerekse baskın ideolojik, dilsel ve kültürel etmenlerin etkisi altında kalan bir birey olarak görmenin daha tutarlı bir yaklaşım olacağı kanısındayız. Her ne kadar bazı araştırmacılar çevirmenin tarafsız olması gerektiğini vurgulasalar da, metni başka bir dile ve dolayısıyla bir kültüre aktaran çevirmenin ideolojik tutumunu metne yansıtması engellenemez, ayrıca, çeviri üzerinde etkisi ve duruma göre söz sahibi olan işverenin de yönlendirmesiyle çevirilerin doğrudan/bilinçli ya da dolaysı/bilinçsiz biçimde ideolojilerin etkisi altında kalması kaçınılmazdır. Alınan her kararla siyasi anlamda olmasa da dünya görüşü, inanç, düşünce biçimi ve değerler açısından ideolojik bazı tercih ve seçimler yapılır. Bu seçimlerin ideolojik nitelikte olduğunu kanıtlayan en belirgin göstergeler, bir kaynak metnin birden fazla çevirisinin karşılaştırılmasıyla ortaya çıkmaktadır. Bu göstergeler genellikle çevirmenin, bazen çevirmenleri sınırlandıran hamilerin, bazen de erek toplumun ve kültürün sesi biçiminde duyulmaktadır. Aslında çeviriler, bütün bu seslerin bir araya geldiği "karma" metinlerdir, ancak bu sesler metnin farklı yerlerinde farklı tonda ve güçte duyulur. Bu yönüyle çeviri, bir anlamda dilsel ve kültürel düzlemde kendini ve toplumu sorgulamaya ve zenginleştirmeye olanak veren en etkili araçlardan biridir.

\section{Notlar}

1 Akarsu'nun Felsefe Terimleri Sözlüğ̈̈’nde de işaret edildiği gibi ideolojinin birkaç anlamı vardır. Birinci anlam, Destutt de Tracy'de olduğu gibi “bilinç olaylarını, idelerin niteliklerini, yasalarını, gösterdikleri anlamlarla bağlantılarını ve köklerini inceler (1998: 101). Bir diğer anlamı ise, "kendine özgü verilere dayanarak geliştiğini sanan, gerçekte ise toplumsal ve ekonomik olayların dile gelişi olan, ancak bunun bilincinde olmayan, hiç değilse bu toplumsal olayların kendisini belirlediğini hesaba katmayan kuramsal düşünce[dir]” (1998: 101).

2 Barrett'in öne sürdüğü gibi, bazı kuramcılara göre, her ne kadar Marx bunu kullanmış olmasa da, ideoloji Marx’a göre bir tür 'sahte bilinç' olarak yorumlanmıştır. Çünkü ona göre ideoloji, "çarpık ya da yetersiz bir dünya görüşü olduğu düşüncesine” (Barrett, 2004: 15-16) dayanmaktadır. Engels ile birlikte 1845-1846 y1llarında birlikte yazdıkları "Alman İdeolojisi”" adlı kitapta Marx, "insanların kafalarında oluşturdukları en olmadık 
hayaller bile, ister istemez, ampirik olarak kanıtlanabilir olan ve maddi temellere dayanan kendi maddi yaşam süreçlerinin yüceltilmiş yansımalarıdır" (Marx/Engels, 2013: 35) görüşünü dile getirip ideolojiyi, tarihi ve gelişimi olmayan bir bilinç biçimi olarak tanımayarak "yaşamı belirleyen bilinç değildir, tersine, bilinci belirleyen yaşamdır" (2013: 35) savını öne sürmektedir.

3 Dil ile ideoloji arasındaki bağa işaret eden araştırmacılardan biri de María Calzada Pérez'e göre ideolojinin bir iktidar aracı olarak dile iç görü kazandırmaktadır (2003: 5). Benzer bir görüşe işaret eden John Thompson, ideolojinin yalnızca sosyal söylemlerde değil, günlük yaşamdaki iletişim dilinde de aranması gerektiğini savunarak ideolojiyi anlamak için dilin irdelenmesi gerektiğini belirtmektedir (1984: 36).

4 Akarsu'nun da altını çizdiği gibi "Humboldt'a göre dil, hazır olarak verilmiş (fertiggegebene) bir şey olarak da düşünülemez, insanın kendisinden zorunlu olarak meydana gelir. Dilin organizması da insanda bulunan genel dil yetisinden (Vermögen) ve insanın söylemeye gereksinmesinden doğar ve bir insan topluluğu içinde meydana gelir" (Akarsu, 1998: 20).

5 Yirminci yüzyılda bu anlayışı sürdüren Walter Benjamin çevrilemezliği, dillerin farklı biçimlerine bağlamaktadır. Çünkü çeviri, her dil gibi, bir biçimdir (Benjamin, 2008: 26) Bu bağlamda, çeviriler kaynak metnin anlamını ya da içeriğini aktarmaya çalışmak yerine, özgün/kaynak metnin biçimine geri dönmeye çalışmalıdır (2008: 26). 1923 yılında Baudelaire'in Tableaux Parisiens' in Almanca çevirisi için yazmıș olduğu "Cevirmenin Görevi" başlı̆ıını taşıyan önsözünde Benjamin, çeviride amacın, anlamanın aktarılmasından çok, diller ve tarih ötesi bir nitelik taşıyan "salt/arındırılmış/saf dile" (reine Sprache) (2008: 29) ulaşmak olduğunu öne sürmektedir. Bu dil bizi, simgesel anlamda insanlığın konuştuğu ve Babil'de dillerin birbirinden ayrılmadığı 'ilk' dile götürmektedir. Bir metnin içerisinde bulunan farklı anlamları başka dillerin biçimleri içerisinde ortaya koyan çeviriler, Benjamin'e göre özgün yapıtın yaşamasına (2008: 27) yol açtı̆̆ından dolayı üstün bir konuma sahiptir.

6 Çalışmada kullanılan ve Türkçe çevrilmemiş olan İngilizce kaynaklardan yapılan doğrudan alıntılar tarafımdan yapılmıştır.

7 Bu tür uygulamaların toplumlar üzerinde baskı uygulayan rejimlerde ya da totaliter yönetimlerde daha sık karşılaşılması, bu anlayışın dışarıdan ithal edilen metinlerde de egemen olduğunu ya da benzer görüşlerin kabul gördüğünü ya da desteklendiğini göstermek için çevirilerin araçsallaştırılarak baskın ideolojinin devamını sürdürme beklentisinin sonucudur.

8 Venuti akıcıllk kavramını, çevirmenin erek okur kitlesinde, hem söz dizimi, hem de anlamsal ifadenin net bir biçimde aktarılması bakımından kolay okunabilirliği sağlaması olarak yorumlamaktadır (1995: 1). Ona göre, çeviri metin ne kadar akıcıysa çevirmen o kadar görünmez olur, diğer bir deyişle, çevirmen yerlileştirme stratejisi kullanarak görünmez bir konuma gelmektedir (1995: 1-2). Çevirmenin çeviride görünürlüğü ya da görünmezliği, Venuti'nin altını çizdiği gibi ideolojik, ekonomik ve kültürel etmenlere bağlı bir olgudur (1995: 19-20). Yerlileştirme stratejisinin aynı zamanda erek kültürün yayınevi politikası, edebi ve siyasi görüşler gibi ideolojik nedenlerle biçimlenebileceğini vurgulayan Venuti'ye göre çevirinin amacı değişse de, yerlileștirme stratejisi her zaman erek kültürün amaçları doğrultusunda biçimlenmektedir (1995: 240-241).

9 Merkez ve çevre kavramı, Even-Zohar'ın Çoğul-Dizge kuramıyla da ilişkilendirilebilir. Even-Zohar çevirilerin erek kültürdeki önemine göre çevirileri konumlandırırken merkezi konumda olan çeviriler, erek kültürde belirleyici ve yazın dizgesine yenilik getirebilmektedir; buna karşın çevresel konumda olan çeviriler, erek kültürde ya da yazında yerel anlayışı benimseyen ya da destekleyen bir işleve sahiptir. Çevirilerin işleve ve etki gücüne göre konumlandırılması görece ve devingen bir süreçtir. Dolayısıyla çevresel konumda olan bir çeviri, zaman içerisinde erek kültürde değişen koşullara bağlı olarak merkez konuma, merkezde olan bir çeviride çevresel konuma gelebilir. Bu nedenle, dizge içerisinden değişen koşullar, merkez-çevre arasında bir çekişmeye de yol açmaktadır. Merkezde olan çeviriler daha çok ilgi gördügünden doğal olarak daha saygın, üstün ve birincil yapitlar olarak görülmektedir (Even-Zohar, 2008: 128-129).

10 Benzer bir yaklaşımı savunan Homi Bhabha, 'arada olma/bulunma' bağlamında, iki tarafa da ait olmayan, dolayısıyla daha bağımsız ve karşıt görüşlere, ikili zıtlıklara yer olmadığından uzlaşmaya açık olan 'üçüncü bir alandan' söz etmektedir. Çevirileri de, başka bir kültürün ürünü olmasına karşın, kendi dilimizde yeniden yazılan ve artık hem/ne kaynak kültüre, hem/ne de erek kültüre ait olması nedeniyle 'üçüncü alanda' bulunan metinler olarak yorumlanabilir $(2000: 34,42)$. 


\section{Kaynaklar}

Akarsu, B. (1998). Felsefe terimleri sözlüğü. İnkılap.

Akarsu, B. (1998b). Wilhelm von Humboldt'ta dil-kültür bağlantıst. İnkılap.

Althusser, L. (1970). Ideology and ideological state apparatuses (B. Brewster, Trans.) Lenin and Philosophy and Other Essays, pp. 142-147, Monthly Review Press, 166-76.

Althusser, L. (2000). İdeoloji ve devletin ideolojik aygıtları (Y. Alp, M. Özışık, Çev.) İletişim.

Aslan, K. (2004). Haber nasıl okunur? Anahtar Kitaplar.

Barrett, M. (2004). Marx 'tan Foucault'ya ideoloji (A. Fethi, Çev.) Doruk.

Bassnett, S. and Lefevere, A. (1990). Translation, history and culture. Pinter Publishers.

Benjamin, W. (2008). Çevirmenin görevi (A. Cemal, Çev.) Çeviri Seçkisi II. Çeviri(bilim) Nedir? Başkasının bakışı (M. Rifat, Ed.) Sel, 25-35.

Bhabha, H. K. (2000). Die Verortung der kultur (M. Schiffmann und J. Freudl, Trans.) Stauffenburg.

Bulut, A. (2008). Basindan örneklerle çeviride ideolojik çeviri. Multilingual.

Eagleton, T. (1981). Edebiyat eleştirisi üzerine (H. Gönen, Çev.) Eleştiri.

Eagleton, T. (1996). İdeoloji: Giriş (M. Özcan, Çev.) Ayrıntı.

Even-Zohar, I. (1990). Introduction [to polysystem studies]. Poetics Today (11:1) (B. McHale, Ed.)

Duke University Press.

Fawcett, P. ve Jeremy, M. (2009). Ideology. Routledge encyclopedia of translation studies. Oxfordshire /Routledge Routledge.

Hatim, B. ve Mason, I. (1990). Discourse and the translator. Routledge.

Hermans, T. (1997). Çeviri anlatıda çevirmenin sesi (A. Bulut, Çev.) Kuram Dergisi, 15, 63-68.

Humboldt, W. von (1988.) On language (P. Heath, Ed) Cambridge University Press.

Kanca, Ö.Y. (2009). Türkiye 'deki gazetelerde dış kaynaklı haberlerin çevirisinde ideolojik yaklaşımlar.

(Yayınlanmamış yüksek lisans tezi) İstanbul Üniversitesi, Sosyal Bilimler Enstitüsü Çeviribilim Anabilim Dal1.

Kazancı, M. (2006). Althusser, ideoloji ve ideoloji ile ilgili son söz. İstanbul Üniversitesi İletişim Fakültesi Dergisi, 24, 67-93.

Larrain, J. (1994). İdeoloji ve kültürel kimlik. Sarmal.

Lefevere, A. (1992). Translation, rewriting and the manipulation of literary fame. Routledge.

Marx, K. ve Engels, F. (2013). Alman ideolojisi (T. Ok ve O. Geridönmez, Çev.) Evrensel.

Mason, I. (2012). Discourse, ideology and translation (M. Baker, Ed.) Critical Readings in Translation, 83-96, Routledge.

Munday, J. (2007). Translation and Ideology. The Translator, 13 (2), 195-217.

Nord, C. (2003). Textanalyse und Übersetzen: Theoretische Grundlagen, Methoden und Didaktische Anwendungen einer übersetzungsrelevanten Textanalyse, Gross.

Schäffner, C. (2003). Third ways and new centres - ideological unity or difference? (M. C. Pérez, Ed.) Aprosos of Ideology: Translation studies on ideology - ideologies in translation studies, 23-41.

TDK (1998). Türkçe Sözlük II (İ. Parlatır, N. Gözaydın, H. Zülfikar, Ed.) Türk Dil Kurumu.

Thompson, J. B. (1984). Studies in theory of ideology. University of California Press. 
Tahir-Gürçağlar, Ş. (2014). The translation bureau revisited: Translation as symbol (M. C. Pérez, Ed.) Apropos of ideology: Translation studies on ideology, ideologies in translation studies, 112-129, Routledge.

(pp.113-129). http://dx.doi.org/10.4324/9781315759937

Thompson, J. B. (2013). İdeoloji ve modern kültür. Kitle iletişim çağında eleştirel toplum kuramı (İ. Çetin, Çev.) Dipnot.

Tymoczko, M. (2014). Ideology and the Position of the Translators: In what sense is a translator in between? (M. C. Perez, Ed.) Apropos of Ideology: Translation studies on ideology - Ideologies in translation studies, 181-201, Routledge.

van Dijk, T. A. (1998). Ideology: A multidisciplinary approach. Sage.

van Dijk, T. A. (2001). Discourse, ideology and context, Folia Linguistica XXX (1-2): 11-40.

Venuti, L. (1995). Translator's invisibility: A history of translation. Routledge.

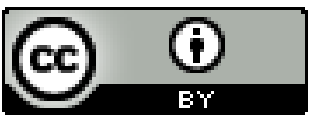

Bu eser Creative Commons Atıf 4.0 Uluslararası Lisansı ile lisanslanmıştır. (This work is licensed under a Creative Commons Attribution 4.0 International License). 